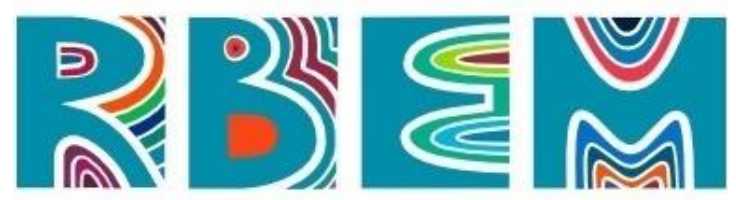

REVISTA BAIANA dE EDUCAÇÃo MATEMÁtICA

$\underline{\text { ARTIGO }}$

dol https://doi.org/10.47207/rbem.v1i.10316

\title{
Discutindo o Método de Ensino por meio da Resolução de Problemas (MERP)
}

\author{
BIAZUTTI, Angela Cássia \\ Professora Associada da Universidade Federal do Rio de Janeiro (UFRJ). Doutora em Matemática pela \\ Universidade Federal do Rio de Janeiro (UFRJ). \\ ORCID: https://orcid.org/0000-0003-3973-1057. E-mail: biazutti@im.ufrj.br.
}

VAZ, Rafael Filipe Novôa

Professor doInstituto Federal de Educação, Ciência e Tecnologia do Rio de Janeiro, Campus Paracambi. Mestre em Ensino de Matemática pela Universidade Federal do Rio de Janeiro (UFRJ). Doutorando em Ensino de

Matemática no PEMAT/UFRJ.

ORCID: https://orcid.org/0000-0002-7266-4661. E-mail: rafael.vaz@ifrj.edu.br.

ANDRADE, Luciano Roberto Padilha de

Professor da Faculdade SENAI/CETIQT. Mestre em Educação Matemática pela Universidade Santa Úrsula. ORCID: https://orcid.org/0000-0002-0649-270X. E-mail: lucpad2013@gmail.com.

Resumo: A reprovação e evasão nas disciplinas de Cálculo nos cursos de graduação vem sendo objeto de pesquisa nas últimas décadas. Nas diferentes instituições de Ensino superior (IES) onde foram coletados dados para as pesquisas do grupo Transição do Projeto Fundão-UFRJ, estas disciplinas apresentam taxas de reprovação e evasão elevadas. Nossos resultados, em consonância com aqueles encontrados na literatura, indicam que o cerne da questão está no ensino e na aprendizagem de funções, pré-requisito básico para a aprendizagem de Cálculo. Neste sentido, ao longo dos últimos nove anos, o grupo Transição vem buscando novas opções didáticas que possibilitem de alguma forma contribuir para minimizar as dificuldades da aprendizagem de funções e, assim, reduzir as taxas de reprovação e evasão nas turmas de Cálculo. O Método de Ensino por Meio da Resolução de Problemas (MERP) consiste em uma sugestão didática e metodológica elaborada pelo grupo Transição para o ensino de Matemática, mais especificamente, para o ensino de funções. Este método é sustentado por três pilares teóricos/metodológicos: o ensino por meio da Resolução de Problemas, o estudo das Representações Semióticas e a utilização do GeoGebra como ferramenta de Ensino. Neste artigo problematizaremos a aprendizagem de Cálculo e discutiremos a utilização do MERP.

Palavras-chave: MERP, Ensino de Funções, Resolução de Problemas, Cálculo Diferencial e Integral

\section{Discussing the Teaching Method through Problem Solving (MERP)}

Abstract: The failure and evasion in the disciplines of Calculus in undergraduate courses has been the object of research in recent decades. In several higher education institutions (HEIs) where data were collected for research by the Fundão-UFRJ Project Transition group, these disciplines have high failure and dropout rates. Our results, in line with those found in the literature, indicate that the core of the issue is in the teaching and learning of functions, a basic prerequisite for learning Calculus. In this 


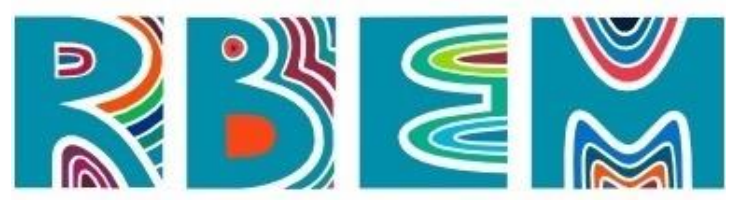

REVISTA BAIANA DE EDUCAÇÃO MATEMÁtICA

sense, over the past nine years, the Transition group has been looking for new didactic options that make it possible to somehow contribute to minimize the difficulties of learning functions and, thus, reduce the failure and dropout rates in the Calculus classes. The Teaching Method through Problem Solving (MERP) consists of a didactic and methodological suggestion developed by the Transition group for the teaching of Mathematics, more specifically, for the teaching of functions. This method is supported by three theoretical / methodological pillars: teaching through Problem Solving, the study of Semiotic Representations and the use of GeoGebra as a teaching tool. In this article we will discuss the learning of Calculus and discuss the use of MERP.

Keywords: MERP, Teaching Functions, Problem Solving in Mathematics, Differential and Integral Calculus

\section{Discutiendo sobre el Método de Enseñanza a través de la Resolución de Problemas (MERP)}

Resumen: El fracaso y la evasión en las disciplinas del Cálculo en las carreras de grado ha sido objeto de investigación en las últimas décadas. En las diferentes instituciones de educación superior (IES) donde los datos fueron recolectados para investigación por el grupo de Transición del Proyecto Fundão-UFRJ, estas disciplinas tienen altas tasas de fracaso y abandono. Nuestros resultados, en línea con los encontrados en la literatura, indican que el núcleo del tema está en la enseñanza y el aprendizaje de funciones, un prerrequisito básico para aprender Cálculo. En este sentido, durante los últimos nueve años, el grupo de Transición ha estado buscando nuevas opciones didácticas que permitan contribuir de alguna manera a minimizar las dificultades de las funciones de aprendizaje y, así, reducir las tasas de reprobación y deserción en las clases de Cálculo. El Método de Enseñanza a través de la Resolución de Problemas (MERP) consiste en una sugerencia didáctica y metodológica desarrollada por el grupo de Transición para la enseñanza de las Matemáticas, más específicamente, para la enseñanza de funciones. Este método se sustenta en tres pilares teórico / metodológicos: la enseñanza a través de la Resolución de Problemas, el estudio de las Representaciones Semióticas y el uso de GeoGebra como herramienta de enseñanza. En este artículo problematizaremos el aprendizaje del cálculo y discutiremos el uso de MERP.

Palabras-Clave: MERP, Funciones didácticas, Resolución de problemas en Matemáticas, Cálculo diferencial e integral.

\section{Introdução}

Há 8 anos o Grupo-Transição do Projeto Fundão-UFRJ pesquisa as dificuldades e barreiras no ensino de Cálculo Diferencial e Integral (CDI). As pesquisas iniciais indicaram haver diversos obstáculos para os cursistas de Cálculo: dificuldades no traçado de gráficos, na leitura e interpretação dos enunciados e na conversão entre as representações algébrica e gráfica.

Desde o final de 2018, o Grupo-Transição começou a construir um método que utiliza a Resolução de Problemas para ensinar alguns conceitos que fazem parte do tópico função e 


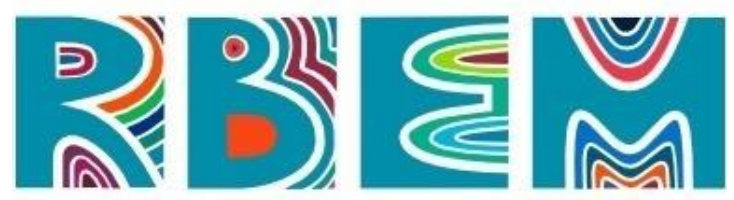

REVISTA BAIANA DE EDUCAÇÃO MATEMÁtICA

de CDI. A abordagem foi inicialmente construída para ser utilizada nas primeiras semanas de aula da disciplina inicial de CDI em um curso de graduação na UFRJ que não inclui PréCálculo em sua grade curricular. No entanto, acreditamos que esta proposta é adequada para ser utilizada, durante todo o semestre, em uma disciplina de Pré-Cálculo.

Consideramos que esta proposta de método de ensino por meio da Resolução de Problemas é diferenciada pois ela é desenvolvida amparada em outras duas ideias: a exploração de diversos registros de representação semiótica e a utilização do software GeoGebra. Ao integrar a Álgebra e a Geometria, este software pode ser utilizado como recurso visual ligado a problemas significativos envolvendo funções, de forma dinâmica. Com o seu auxílio o aluno pode criar figuras que ajudem a interpretar problemas e pode explorar registros de representação analíticos e gráficos para as funções.

Na primeira seção, faremos uma breve explanação sobre as dificuldades e caminhos para o ensino de CDI encontrados na literatura e nas pesquisas do Grupo-Transição. Nas cinco seções seguintes apresentaremos um Método de Ensino por meio da Resolução de Problemas (MERP). Na penúltima seção, apresentaremos alguns exemplos de problemas explorados por meio do MERP. Na última seção, apresentamos nossas considerações finais sobre o método.

\section{Problematizando o Ensino de Cálculo}

Há vários anos, o alto índice de reprovação em CDI, tanto em universidades públicas como particulares, tem despertado o interesse de pesquisadores e o temor dos estudantes. Entre 1990 e 1995 a taxa de reprovação em CDI na USP variava entre $20 \%$ e $70 \%$ (BARUFI, 1999), na UFF, entre 1996 e 2000 a taxa de reprovação variava entre $45 \%$ e a alarmante taxa de 95\% (REZENDE; 2003) e na UFRRJ, a taxa de reprovação entre 2011 e 2013 foi de 75\% (SANTOS et al, 2016).

As taxas de reprovação estão diretamente associadas às taxas de evasão. Para realizar um comparativo e destacar a gravidade do problema podemos observar algumas taxas de evasão no ensino superior. Entre 2009 e 2014, de acordo com os dados do Censo da Educação Superior, a graduação em Direito acumulou uma evasão de aproximadamente $45 \%$, nas Engenharias Metalúrgica e Mecânica a taxa foi de 60\%, enquanto nos cursos de Matemática, 


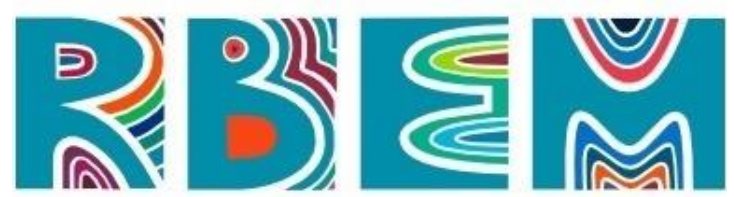

REVISTA BAIANA DE EDUCAÇÃO MATEMÁtICA

a evasão atinge 90\% dos alunos do curso (SACCARO; FRANCA; JACINTO, 2019).

Cálculo é, epistemologicamente, um conteúdo difícil de ser ensinado e de ser aprendido. "Se o obstáculo não for apenas nosso ou de algumas outras pessoas, mas for mais generalizado, ou foi generalizado em alguma época ou em alguma cultura, então ele é conhecido como um obstáculo epistemológico" (SIERPINSKA, 1992, p. 28). No entanto, diversas causas para essa dificuldade são apresentadas na literatura. Oliveira, Gonçalves e Piasson (2018) realizaram um mapeamento dos artigos, teses e dissertações que tratam de ensino de CDI com o uso do GeoGebra, entre os anos de 2010 a 2018. Neste estudo, os autores identificaram como principais causas para o baixo rendimento dos estudantes a falta de base, as falhas metodológicas de ensino dos professores, as falhas na estrutura curricular dos cursos e a complexidade dos conceitos.

Diversos trabalhos têm investigado o alto índice de evasão e reprovação na primeira disciplina de CDI e as principais causas para as dificuldades na transição do Ensino Médio para o Superior, que se refletem nas dificuldades na aprendizagem dessa disciplina. Entre eles estão os trabalhos de Rezende (2003), Gonçalves (2007), Cury e Bortoli (2011), Masola e Allevato (2016) e Torres e Havelange (2017). Vários deles atribuem o alto índice de reprovação em CDI à carência de alguns conteúdos pelos discentes no contexto da Matemática básica, apresentando-se como obstáculo à compreensão dos diversos temas do CDI, mas este, definitivamente, não é o único obstáculo.

Rezende (2003) alerta que as aulas de CDI, em geral, preparam os estudantes apenas para as avaliações, priorizando exercícios e demonstrações no quadro, o "como fazer" em detrimento do raciocínio sobre "o quê" e "por quê. Segundo Andrade (2020, p. 51), "como consequência, ocorre o fracasso no ensino de Cálculo devido, principalmente, às dificuldades de natureza epistemológica, especificamente, pelas ideias exploradas no processo ensinoaprendizagem de CDI não serem, em geral, trabalhadas na Educação Básica”.

Em relação às contribuições encontradas na literatura para minimizar esse problema, destacam-se: a utilização de novas abordagens metodológicas; melhor preparação do professor quanto ao conteúdo ensinado e suas práticas pedagógicas; o uso intensivo de TICs (Tecnologias de Informação e Comunicação) e do GeoGebra; introdução do ensino de CDI no Ensino Médio (OLIVEIRA; GONÇALVES; PIASSON, 2018). Estas tendências se articulam com as identificadas por Andrade (2020): a inserção de noções de CDI no Ensino 


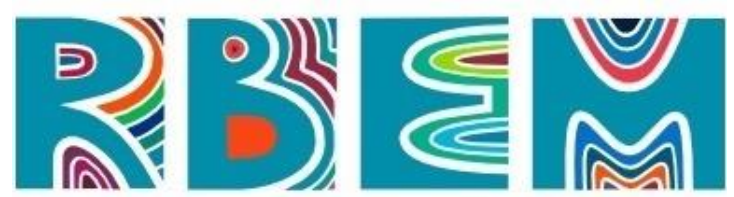

REVISTA BAIANA DE EDUCAÇÃO MATEMÁTICA

Médio; métodos diferenciados para o ensino de CDI; reforço, tutoria ou monitoria e a inserção do Pré-Cálculo na graduação.

Várias pesquisas do grupo Transição do Projeto Fundão-UFRJ também foram realizadas, a partir de 2012, para compreender as dificuldades na aprendizagem de CDI e apontar caminhos que possam minimizar as dificuldades encontradas por docentes e discentes nas disciplinas de CDI (sobretudo na inicial). Um dos trabalhos do grupo Transição é o de Sousa e Andrade (2016), que sugere, para minimizar as dificuldades dos alunos com o traçado de gráficos de funções, realizar atividades de construção de gráficos a partir de transformações no plano, utilizando softwares.

Outros trabalhos do grupo são os de Biazutti, Nasser, Torraca, Barros e Oliveira (2018), Nasser, Biazutti, Torraca e Barros (2019) e Nasser, Biazutti, Barros e Vaz (2019), que apontam para as dificuldades dos alunos com a compreensão do conceito de função, a leitura e interpretação de enunciados de problemas, a conversão entre os registros de representação verbal e analítico, analítico e gráfico e o trato algébrico. Estes trabalhos recomendam como possível solução para estas dificuldades, a exploração de resolução de problemas envolvendo conversão de registros de representação de funções, de preferência com auxílio de softwares.

O tópico de otimização de funções permite explorar problemas muito interessantes e ricos, de modo a abordar estas dificuldades dos alunos de forma bastante dinâmica, utilizando o software GeoGebra, conforme exposto em outro trabalho do grupo, de autoria de Biazutti, Vaz e Ferreira (2018).

O trabalho de Biazutti, Andrade e Vaz (2020) expõe um levantamento mais detalhado das diferentes pesquisas do grupo Transição e apresenta sugestões de atividades envolvendo problemas de otimização e utilização do software GeoGebra. A partir daí, surgiu a ideia do MERP, desenvolvida em detalhes neste artigo, dando continuidade e ampliando significativamente o referido texto apresentado no IX Seminário de Pesquisa em Educação Matemática do RJ, em 2020.

\section{Registros de Representação Semiótica e o Ensino de Funções}

Para que os estudantes apresentem um bom desempenho em Matemática é necessário que eles consigam identificar e diferenciar o objeto matemático, por exemplo a ideia de 


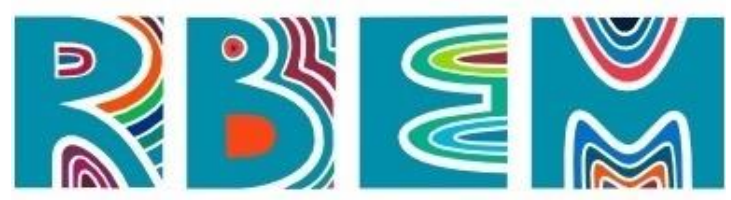

REVISTA BAIANA DE EDUCAÇÃO MATEMÁTICA

função, de uma de suas representações semióticas, por exemplo, seu gráfico no plano cartesiano (DUVAL, 2009). Duval (2012) afirma que as representações semióticas de um objeto matemático são necessárias para a compreensão dos conceitos. Segundo o pesquisador,

os objetos matemáticos não estão diretamente acessíveis à percepção ou à experiência intuitiva imediata, como são os objetos comumente ditos "reais" ou "físicos". É preciso, portanto, dar representantes. E por outro lado, a possibilidade de efetuar tratamentos sobre os objetos matemáticos depende diretamente do sistema de representação semiótico utilizado" (DUVAL, 2012, p. 268).

A importância da utilização do registro adequado pode ser observada nas quatro operações aritméticas básicas, ou utilizando algarismos romanos ou números indo-arábicos. A utilização de um melhor registro possibilitou não somente a realização dessas operações, de forma mais clara e simples, ao longo da história, como o próprio desenvolvimento da Matemática. De modo similar, podemos associar a utilização da base dois à construção e evolução dos computadores.

Duval (2012) considera a existência de um paradoxo cognitivo do pensamento matemático:

de um lado, a apreensão dos objetos matemáticos não pode ser mais do que uma apreensão conceitual e, de outro, é somente por meio de representações semióticas que a atividade sobre objetos matemáticos se torna possível. Este paradoxo pode constituir-se num grande círculo para a aprendizagem. Como os sujeitos em aprendizagem poderiam não confundir os objetos matemáticos com as suas representações semióticas, se eles podem tratar apenas com as representações semióticas? (DUVAL, 2012, p. 168)

É comum, mesmo entre professores, associar a ideia de função apenas à sua representação algébrica. Como se a lei fosse a função, em si, enquanto o gráfico no plano cartesiano fosse a representação dessa lei. Outro exemplo desta crença pode ser observado na dificuldade da população brasileira, mesmo dentre as pessoas mais instruídas, em reconhecer o crescimento exponencial (ou similar) a partir de um gráfico com o número de casos de contaminados com a COVID-19.

Os conceitos matemáticos somente serão acessíveis por meio da mobilização de pelo menos dois registros de representação semiótica (DUVAL, 2009). Biazutti e colaboradores (2018) consideram, no estudo de funções, a existência de quatro diferentes tipos de representação semiótica no estudo de funções: gráfica, tabular, algébrica e a língua materna. 


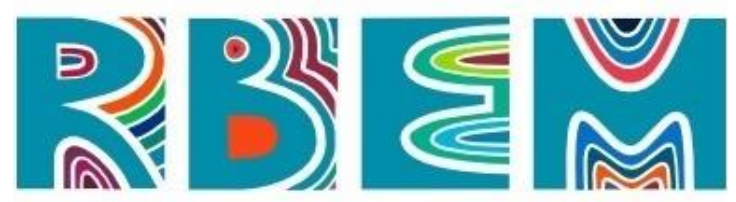

REVISTA BAIANA DE EDUCAÇÃo MATEMÁTICA

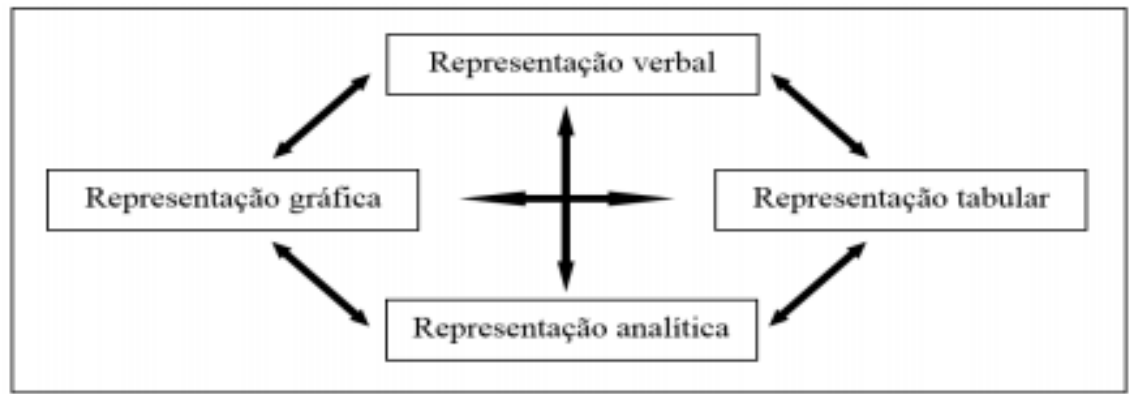

Figura 1 - Registros de Representação para funções (Fonte: BIAZUTTI et al, 2018)

Quando o estudante consegue estabelecer relações entre estas, a aprendizagem se estabelece. Os dois tipos de atividades semióticas são: tratamento e conversão. O tratamento é uma transformação realizada dentro do mesmo registro. Por exemplo quando um estudante reconhece que $f(x)=(x+2)^{2}$ é equivalente a $f(x)=x^{2}+4 x+4$. A conversão, por sua vez, ocorre quando há mudança de um registro para o outro sem alterar os objetos matemáticos correspondentes. Por exemplo quando o estudante associa a representação algébrica $\mathrm{f}(\mathrm{x})=$ $(\mathrm{x}+2)^{2}$ à sua representação gráfica no plano cartesiano.

Duval (2012, p. 270) defende que "o funcionamento cognitivo do pensamento humano se revela inseparável da existência de uma diversidade de registros semióticos de representação". Segundo o autor, não há 'noesis' sem 'semiose', ou seja, não há a apreensão conceitual de um objeto sem que haja a apreensão ou a produção de uma representação semiótica.

No entanto, é essencial, na atividade matemática, poder mobilizar muitos registros de representação semiótica (figuras, gráficos, escrituras simbólicas, língua natural, etc...) no decorrer de um mesmo passo, poder escolher um registro no lugar de outro. E, independentemente de toda comodidade de tratamento, o recurso a muitos registros parece mesmo uma condição necessária para que os objetos matemáticos não sejam confundidos com suas representações e que possam também ser reconhecidos em cada uma de suas representações. (DUVAL, 2012, p. 270)

\section{O GeoGebra como ferramenta de Ensino}

A utilização de recursos computacionais no ensino pode incentivar à reflexão e ao desenvolvimento do lado cognitivo de cada aluno, principalmente por respeitar o ritmo de aprendizagem de cada um, deixando que os estudantes aprendam com seus erros. Segundo Abramovich (2013), a utilização destes recursos possibilita comunicar ideias matemáticas 


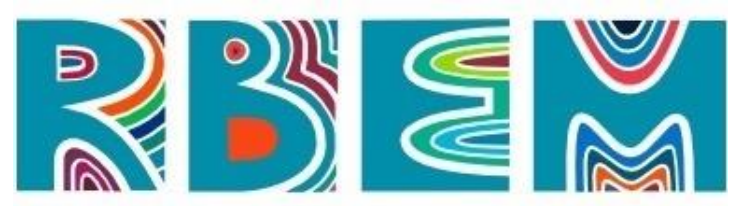

REVISTA BAIANA DE EDUCAÇÃO MATEMÁTICA

importantes, presentes em um tópico curricular banal e estudar tópicos mais difíceis de outra forma.

A utilização de ferramentas tecnológicas para resolução de problemas aparece na Competência 5 da BNCC:

Compreender, utilizar e criar tecnologias digitais de informação e comunicação de forma crítica, significativa, reflexiva e ética nas diversas práticas sociais (incluindo as escolares) para se comunicar, acessar e disseminar informações, produzir conhecimentos, resolver problemas e exercer protagonismo e autoria na vida pessoal e coletiva (BRASIL, 2017, p.9.)

A escolha do Geogebra se deu pelo fato do software ser livre. Dessa forma, pode ser instalado em quantos dispositivos forem necessários ou até mesmo utilizado diretamente on line, o que facilita o acesso dos estudantes. O Geogebra é um software de Matemática Dinâmica, gratuito e multiplataforma, o que permite ser trabalhado em diferentes níveis de ensino. Possui muitos recursos interativos e dinâmicos que podem ser aplicados facilmente em sala de aula, dessa forma tornando-se uma ferramenta facilitadora para o processo de ensino e de aprendizagem.

Gerônimo, Barros e Franco (2010) destacam o uso do Geogebra.

Podemos utilizar sua interface gráfica e suas ferramentas para traçar retas, ângulos, circunferências etc. uma das vantagens do uso do GeoGebra é que as construções são dinâmicas, isto é, sem a perda dos vínculos geométricos. Isso permite que o usuário faça grande quantidade de experimentações que lhe possibilite construir proposições geométricas (2010, p. 11).

Em sua pesquisa sobre os efeitos da utilização do GeoGebra no processo de aprendizagem de alunos em uma escola na Malásia, Arbain e Shukor (2015) descrevem o aumento da autoconfiança e da motivação. Relatam que aumentou a livre comunicação entre os alunos e o professor e outros alunos. Os alunos são atraídos naturalmente por ferramentas tecnológicas. Houve uma melhora nítida entre os alunos do grupo que utilizou GeoGebra, comparados aos alunos do grupo de controle, que não utilizaram o GeoGebra.

Para o professor, as vantagens do software são: dinamizar a aula e despertar o interesse do aluno. Devido ao software possuir uma conectividade mundial, pode-se trocar informações e/ou experiências, ensinando e aprendendo com essa interação. As 


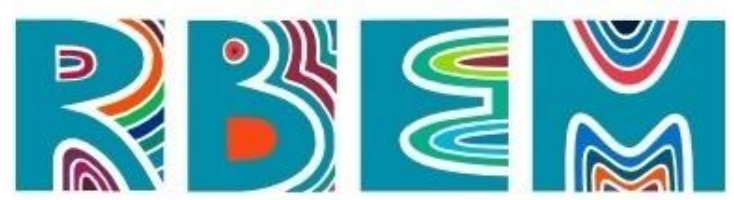

REVISTA BAIANA DE EDUCAÇÃO MATEMÁtICA

características do software educacional GeoGebra permitem explorar as representações analítica e gráfica de uma função e transitar entre elas. Um recurso importante deste software permite simulações dinâmicas além das estáticas, ou seja, situações tipo "vídeo", além da opção tipo "foto". Neste sentido, a utilização do GeoGebra não deve então se limitar à representação geométrica de algumas situações estáticas como a exibição do gráfico de uma função específica. Com os softwares de construção de gráfico que oferecem uma perspectiva dinâmica, como o GeoGebra, é possível oferecer aos estudantes, através do controle deslizante, como mostra a figura 2, possibilidades de explorar o conceito e as propriedades de um jeito inimaginável há décadas.

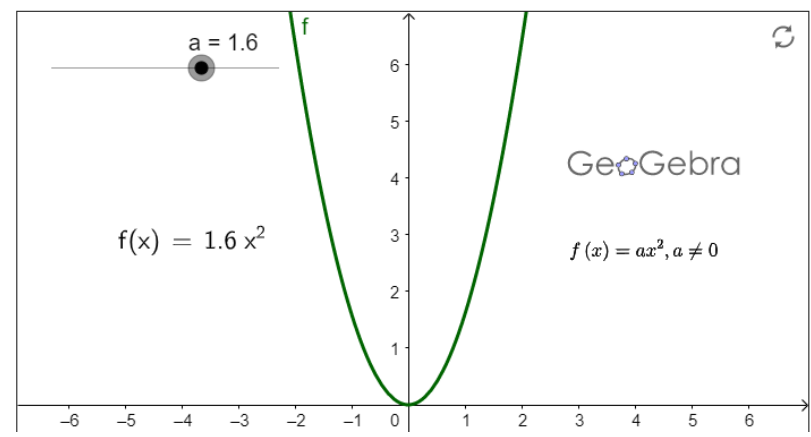

Figura 2 - Controle deslizante no GeoGebra (elaborada pelos autores)

Esta interface dinâmica pode ser utilizada para realizar transformações semióticas entre os sistemas algébrico e geométrico, auxiliando o estudo de funções reais do CDI. Esta prática diversifica o processo de aprendizagem na medida em que possibilita ao aluno uma ferramenta tecnológica para solução de problemas. Como já foi mencionado em outra seção, as nossas investigações identificaram que, dentre as diversas barreiras para a aprendizagem do CDI, estão as dificuldades na compreensão do conceito de função, a dificuldade em realizar as conversões entre suas diferentes representações possíveis e a dificuldade com a modelagem de problemas envolvendo funções.

\section{Ensino por meio da Resolução de Problemas}

Em consonância com as ideias de Krulik e Rudnik (1993), interpretamos como um problema toda atividade que traga ponto ainda inexplorado, que se configure ao estudante como um desafio, algo que possibilite-o sair da zona de conforto. Um problema é uma tarefa 


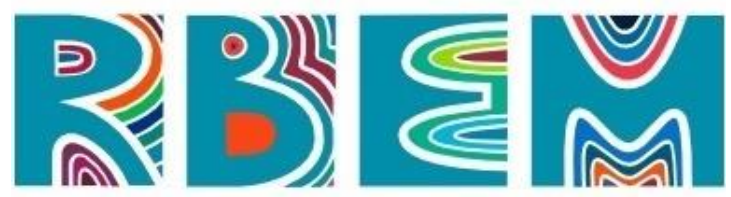

REVISTA BAIANA DE EDUCAÇÃO MATEMÁTICA

que essencialmente não se resolve com procedimentos memorizados. Se os procedimentos para a resolução de uma tarefa escolar estão previamente contidos em algum algoritmo já aprendido pelo estudante, esta tarefa não é mais um problema. Um problema deve proporcionar uma pequena dose de investigação e exploração, para ocorrer a descoberta.

A resolução de problemas, geralmente, está relacionada a uma prática pedagógica em que o professor ensina determinadas técnicas e o estudante resolve cada questão com apenas uma forma de solução. Esta perspectiva está associada aos estudos de Polya (1978), pois seu foco está em "descobrir como resolver problemas e como ensinar estratégias que levem a enxergar caminhos para resolver problemas" (ONUCHIC; ALLEVATO, 2011, p. 77-78).

Onuchic e Allevato (2011, p. 78-79) esclarecem que, apesar do foco ser colocado sobre os processos de pensamento matemático e de aprendizagem através da descoberta, não havia, neste momento histórico, "concordância quanto à forma pela qual esse objetivo seria alcançado", pois os professores e educadores interpretavam de modo distinto o significado de utilizar a "resolução de problemas" na aprendizagem da matemática escolar.

Há três modos de abordar Resolução de Problemas, que podem ajudar a entender e a refletir sobre essas diferenças de entendimento ou de abordagem que se faziam presentes, com maior ou menor intensidade, no contexto do ensino: (1) ensinar sobre resolução de problemas; (2) ensinar matemática para resolver problemas; e (3) ensinar matemática através da resolução de problemas (ONUCHIC; ALLEVATO, 2011, p. 79).

\section{MERP - Método de Ensino por meio da Resolução de Problemas}

O método de ensino por meio da resolução de problemas proposto neste texto utiliza esta terceira perspectiva, pois "o problema é visto como ponto de partida para a construção de novos conceitos e novos conteúdos" (ONUCHIC; ALLEVATO, 2011, p. 80). Esta forma de ensino, segundo Matos e Serrazina (1996), deve possibilitar aos estudantes investigar o conteúdo matemático e adquirir confiança neste processo.

Sendo assim, propomos neste texto a utilização do que denominamos de Método de Ensino por meio da Resolução de Problemas (MERP). Este método consiste na utilização de resolução de problemas como ponto de partida para o ensino de determinados conceitos, com apoio de diferentes representações semióticas e do software GeoGebra, conforme mostra a figura 3. 


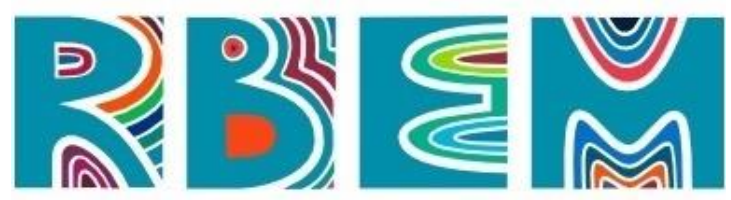

REVISTA BAIANA dE EDUCAÇÃo MATEMÁTICA

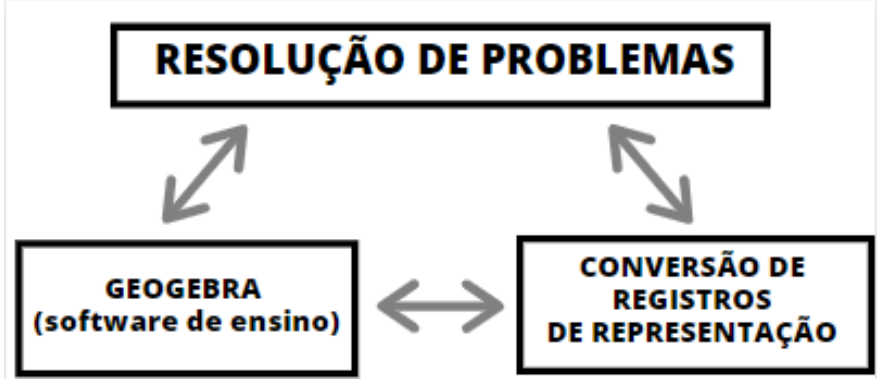

Figura 3 - MERP (Elaborada pelos autores)

Por este método, um conceito é desenvolvido formalmente depois de surgir, de maneira natural e intuitiva, na compreensão ou resolução de um problema. Neste capítulo utilizaremos o MERP para facilitar a compreensão dos conceitos, relacionados a função, na perspectiva do ensino de Pré-Cálculo. Os problemas selecionados para implementar este método devem explorar, prioritariamente, a conversão de registros. Neste sentido, softwares dinâmicos de construção de gráficos, como o GeoGebra, pelas suas próprias características, podem ser utilizados, tanto pelo professor como pelos alunos, para viabilizar uma discussão mais rica sobre diferentes registros de representações de um mesmo objeto.

Tais softwares possibilitam também a representação geométrica de funções descritas verbalmente nos enunciados de diversos problemas, explorando-as de modo dinâmico e interativo como, por exemplo, em investigações relacionadas aos seus máximos e mínimos. Serão explorados neste artigo problemas envolvendo otimização de funções.

Os problemas selecionados foram pensados para utilizar o MERP, no entanto, também podem ser utilizados para consolidar a aprendizagem de conceitos já previamente conhecidos pelos alunos. De modo análogo, estes problemas foram escolhidos para serem utilizados em turmas de Pré-Cálculo e/ou na introdução da disciplina inicial de CDI, entretanto, consideramos que tanto os problemas, quanto o método, podem ser utilizados na Educação Básica.

Na próxima seção apresentaremos alguns exemplos de problemas que podem facilitar a aprendizagem de conceitos relacionados a função quando for utilizado este método. 


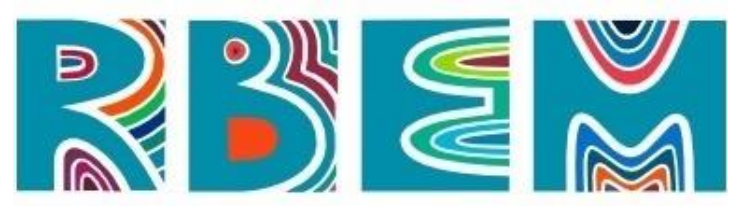

REVISTA BAIANA DE EDUCAÇĀO MATEMÁTICA

\section{Discutindo Problemas com o MERP}

Diversas pesquisas já mencionadas apontam que a maioria dos problemas do Cálculo estão associados à falta de uma representação geométrica corretamente associada à representação via linguagem verbal, observados, principalmente, em diversos problemas de otimização de funções. Em geral, a dificuldade dos alunos nesses problemas não é na aplicação dos conceitos de CDI, mas na dificuldade dos discentes em fazer uma representação geométrica que permita a identificação da relação entre os elementos da figura e os conceitos e na identificação da função envolvida, a partir das informações do enunciado. Os problemas que serão apresentados a seguir foram escolhidos de modo a explorar estes aspectos de Matemática em que os alunos mostraram dificuldades, utilizando o MERP como ferramenta pedagógica.

O primeiro problema envolve otimização de uma função de uma variável, a ser identificada pelos alunos, a partir das informações fornecidas. A solução dele envolve conceitos geométricos e também manipulação algébrica, de modo a que sejam discutidas em

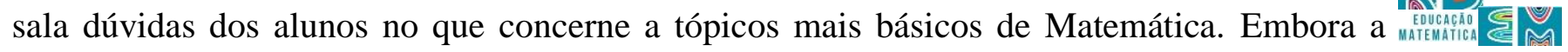
função envolvida não seja polinomial de grau inferior a três, o problema pode ser resolvido, algebricamente, utilizando apenas outros conteúdos do currículo do Ensino Médio, como a desigualdade das médias, que faz parte dos tópicos de Estatística. O software GeoGebra pode ser utilizado para estimar graficamente a solução explorando operações com funções. A sequência didática proposta para discutir o problema utiliza a conversão entre os registros de representação algébrica e geométrica para facilitar a compreensão e solução do problema por parte dos alunos. Este problema também pode ser utilizado para introduzir, de modo intuitivo, o conceito de derivada, associado a uma reta tangente ao gráfico da função.

\section{Problema 1:}

Deseja-se construir uma piscina com fundo horizontal e quatro paredes verticais, de modo que cada seção horizontal seja formada por dois lados opostos retos e paralelos de mesmo comprimento b e por outros dois que têm formato de semicircunferências, de mesmo raio r, 


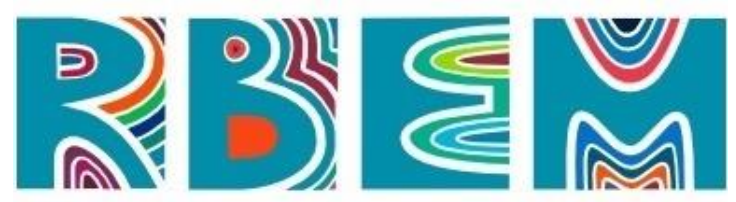

REVISTA BAIANA DE EDUCAÇÃO MATEMÁTICA

ambas côncavas para o mesmo lado, conforme mostra a figura 4. Sabe-se que cada seção horizontal da piscina precisa ter $200 \mathrm{~m}^{2}$ de área.

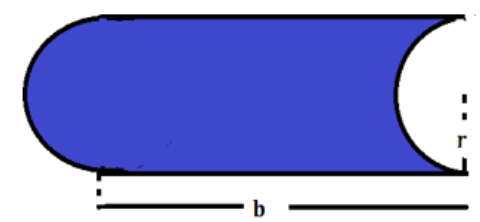

Figura 4 - Seção horizontal da piscina (elaborada pelos autores)

a) Determine a relação entre a base b e o raio $r$ em cada seção da piscina.

b) Utilize o Geogebra para reproduzir a figura 4 e crie controles deslizantes para variar o comprimento da base $b$ ou do raio $r$ e observar o que ocorre com o perímetro da seção, mantida sua área.

c) Determine uma expressão algébrica para o perímetro da piscina, como função do raio das semicircunferências.

d) Determine as dimensões da piscina de perímetro mínimo e qual será a medida deste perímetro, utilizando o resultado obtido no item (c) e a desigualdade das médias.

e) Utilize o GeoGebra para obter o gráfico da função do item (c) e, com auxílio dele e de retas tangentes ao gráfico, estimar o perímetro mínimo. Sugira uma relação entre o ponto onde ocorre o mínimo e a reta tangente ao gráfico neste ponto. Compare o valor de r para o perímetro ser mínimo obtido pelo GeoGebra com o valor obtido em (d). Explique a discrepância.

A desigualdade das médias estabelece que, se $\mathrm{a}_{1}, \mathrm{a}_{2}, \ldots, \mathrm{a}_{\mathrm{n}}$ são positivos, então $\frac{a_{1}+a_{2}+. . a_{n}}{n} \geq \sqrt[n]{a_{1} a_{2} . . a_{n}}$ e a igualdade só ocorre quando $\mathrm{a}_{1}=\mathrm{a}_{2}=\ldots=\mathrm{a}_{\mathrm{n}}$. O valor mínimo de $\mathrm{f}$ ocorrerá quando $\mathrm{r}=\frac{10}{\sqrt{\pi}}$. Nesse caso $\mathrm{b}=10 \sqrt{\pi}$, para que a área da piscina seja de $200 \mathrm{~m}^{2}$. Utilizando o GeoGebra, pode-se obter diretamente o gráfico da função f, apresentado na figura 5. Entretanto, não há como determinar visualmente, de modo preciso, o valor de ' $r$ ' para que o perímetro seja mínimo (com uma certa paciência encontramos 5,6 $<\mathrm{r}<5,7$ ) porque o valor é um número irracional. Um estudo geométrico das retas tangentes ao gráfico em pontos próximos do ponto de mínimo mostrará que a reta tangente no ponto de mínimo deve ser horizontal, como mostra a figura 5. Ao observar a janela de álgebra correspondente 


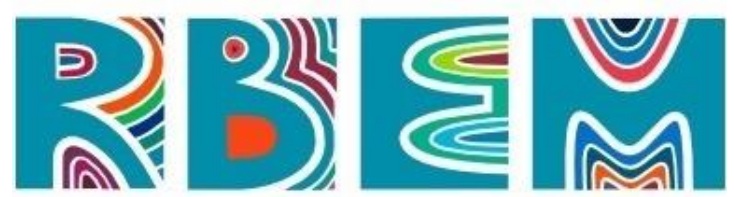

REVISTA BAIANA DE EDUCAÇÃO MATEMÁtICA

a esta reta, verifica-se que o valor de ' $r$ ' procurado aparenta ser um número racional, por conta das aproximações nos cálculos realizados pelo software. É importante apresentar aos alunos, além das vantagens, as limitações que um software pode apresentar.

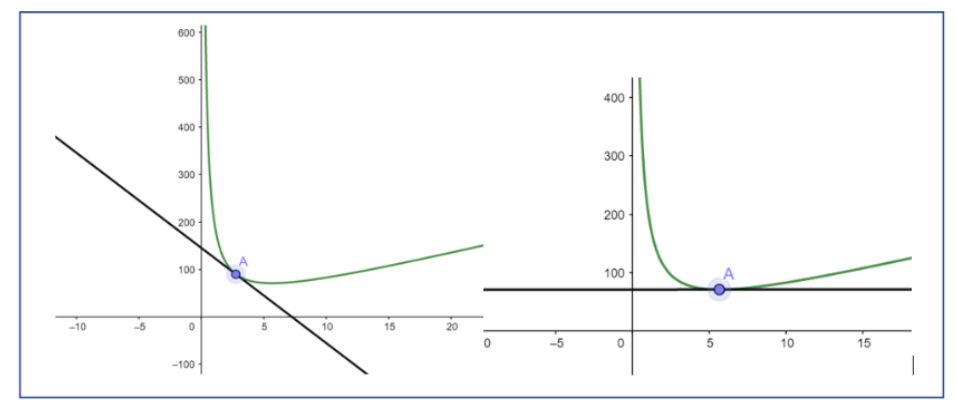

Figura 5 - Representações gráficas da função e das retas tangentes do problema 1 (elaborada pelos autores)

O segundo problema apresenta uma investigação sobre função bem diferente do que é feito, em geral, na Educação Básica. Numa disciplina de CDI ele seria resolvido utilizando derivada e suas propriedades. Ao excluir esta ferramenta matemática e utilizar o MERP, este problema permite introduzir de forma intuitiva os conceitos de máximos e mínimos

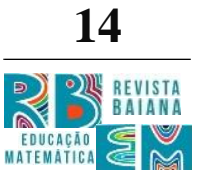
(locais/relativos e globais/absolutos em um intervalo). É possível explorar em profundidade funções crescentes e decrescentes e abordar a associação entre máximos e mínimos (locais/relativos) de uma função com seus intervalos de crescimento e decrescimento e também a relação entre o máximo e mínimo (global/absoluto) com o intervalo de definição da função considerada. A compreensão destes conceitos é importante para um bom resultado dos alunos, mais tarde, em disciplina de CDI.

\section{Problema 2:}

Considere a função $\mathrm{g}(\mathrm{x})=x^{3}-4 x^{2}-3 x+18$, sendo $\mathrm{x} \in \mathrm{I}_{1}=[-2,5]$.

a) Utilize o Geogebra para esboçar o gráfico de $\mathrm{g}$ em $\mathrm{I}_{1}$ e determinar os valores de $\mathrm{x}$ onde $\mathrm{g}$ atinge seu mínimo e seu máximo (globais/absolutos) em $\mathrm{I}_{1}$.

b) Utilize as ferramentas de reta tangente e de reta perpendicular do Geogebra para verificar que a reta tangente ao gráfico de $\mathrm{g}$ no ponto $\mathrm{B}$, de abcissa $\mathrm{x}=\frac{-1}{3}$ é uma reta horizontal. 


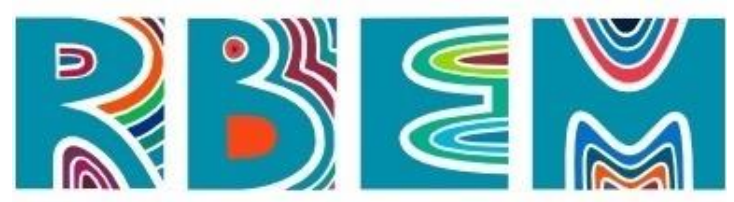

REVISTA BAIANA DE EDUCAÇÃO MATEMÁtICA

b) Especifique cada intervalo de variação de $\mathrm{x}$, dentro do intervalo $\mathrm{I}_{1}$, em que a função $\mathrm{g}$ é crescente e onde g é decrescente e relacione com o mínimo (local/relativo) e com o máximo (local/relativo) de g em $\mathrm{I}_{1}$.

c) Considere agora o intervalo $I_{2}=[-1,2]$. Investigue os valores máximo/mínimo local e global de g neste intervalo e determine se os valores de $\mathrm{g}$ em $\mathrm{I}_{2}$ são sempre positivos, utilizando as informações dos itens anteriores.

d) Seja $\mathrm{f}(\mathrm{x})=\frac{1}{g(x)}$, com $\mathrm{t} \in \mathrm{I}_{2}$. Utilize as informações sobre $\mathrm{g}$ obtidas nos itens anteriores para determinar os intervalos onde f é crescente e onde é decrescente, dentro do intervalo $\mathrm{I}_{2}$, e para determinar os valores máximo/mínimo global e local de f neste intervalo. Esboce um

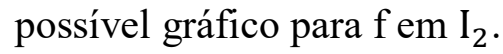

e) Utilize o Geogebra para esboçar o gráfico de $\mathrm{fem}_{2}$ e compare com o obtido no item d).

$\mathrm{O}$ item b) revisa conceitos geométricos de retas paralelas e perpendiculares vistos na Educação Básica, ao mesmo tempo que apresenta o conceito de reta tangente a uma curva em um ponto dado, que estava associado somente a retas tocando circunferências em um único ponto, com o significado que lhe é atribuído em CDI, conforme mostra a figura 6 , a seguir.

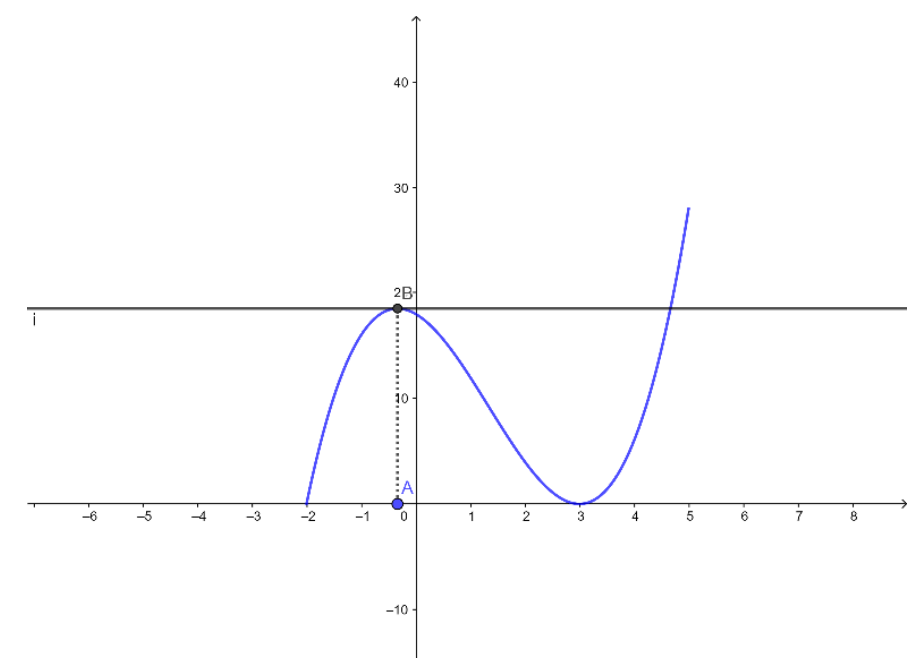

Figura 6 - Reta tangente ao gráfico de g no ponto B (elaborada pelos autores)

O problema 2 permite ainda explorar em sala de aula vários outros conceitos interessantes, a partir da mudança do intervalo de definição de g e suas implicações para o gráfico de f, tais como concavidade para cima ou para baixo em um intervalo, a possibilidade do gráfico ter "bicos" ou assíntotas. 


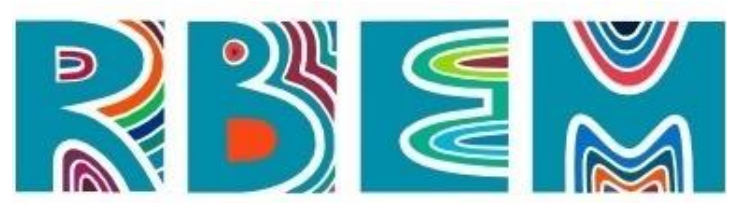

O terceiro problema foi selecionado porque apresenta uma situação problema que pode ser representada por duas funções distintas. É importante para que os alunos tenham confiança em suas formas de resolver, não se preocupem demais em comparar a sua forma de pensar com a de outros colegas ou do professor. O Geogebra é perfeito aqui para representar a situação problema geometricamente e de forma dinâmica, de modo a compreender o problema e procurar a melhor forma de obter a solução procurada.

\section{Problema 3:}

Numa cidade vai ser construído um túnel no qual cada seção transversal será limitada pelo semicírculo $x^{2}+y^{2}=a^{2}$, a $>0$, e pela reta $\mathrm{y}=0$. A área destinada aos veículos ocupará uma seção transversal retangular, com um lado sobre a reta $y=0$ e inscrita na seção transversal do túnel, conforme a figura 7.

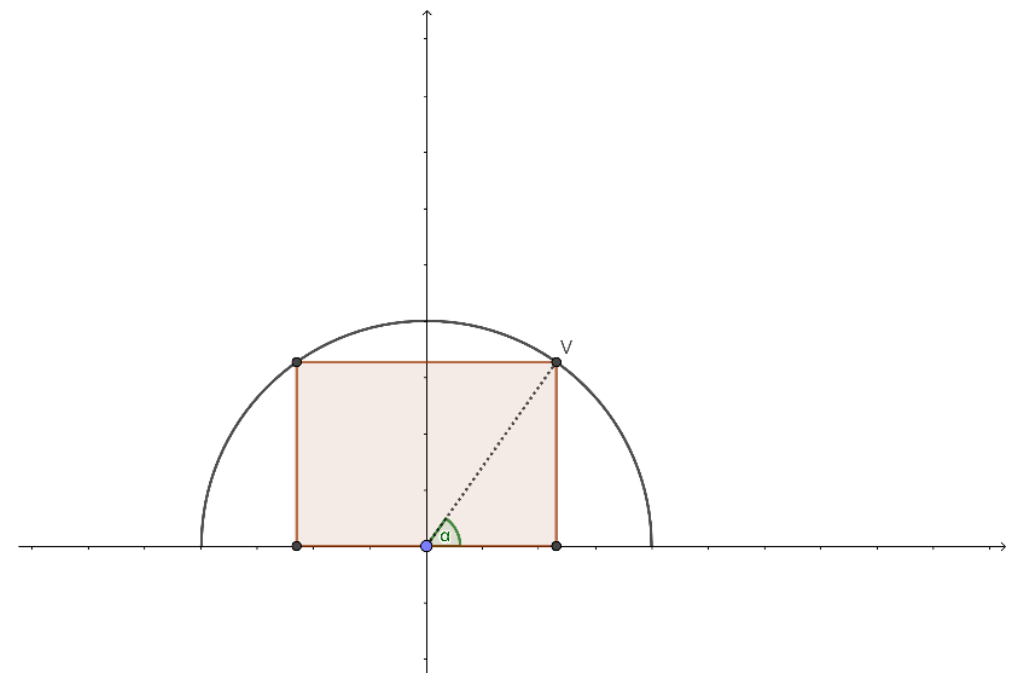

Figura 7 - Seção transversal do túnel com o retângulo inscrito vértice V e ângulo $\alpha$ (elaborada pelos autores)

a) Utilize os comandos dinâmicos do GeoGebra para reproduzir a figura 7 e estudar as alterações no retângulo quando o vértice $\mathrm{V}$ se move ao longo do semicírculo, desde o ponto $(a, 0)$ até o ponto $(0, a)$.

b) Utilize os comandos dinâmicos do GeoGebra para estudar as alterações no ângulo $\alpha$ quando o vértice $\mathrm{V}$ se move.

c) Designe por x a abcissa do vértice V. Determine uma expressão algébrica para a área do retângulo como função de $\mathrm{x}$. 


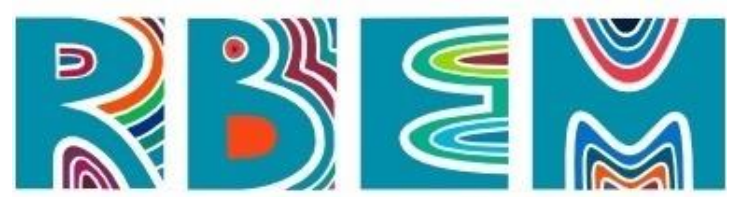

REVISTA BAIANA DE EDUCAÇÃO MATEMÁTICA

d) Determine uma expressão algébrica para a área do retângulo como função de $\alpha$.

e) Determine o retângulo de área máxima (de modo a ter uma boa ventilação), possível de ser inscrito no semicírculo de raio $a$, e qual será a medida de sua base e altura.

f) Usando o resultado do item e), determine, se possível, o valor mínimo do raio a para que o túnel possa ter duas faixas de rolamento, com 3,5m cada e seja acessível a veículos com até $5,5 \mathrm{~m}$ de altura, em qualquer ponto das faixas.

A área do retângulo, definida por $\mathrm{A}=\mathrm{B} . \mathrm{H}$, pode ser representada pela imagem da função $A=f(x)$, onde a variável $x$ representa a metade da base $B$ e a altura $H$ é o valor da ordenada do ponto de abcissa $\mathrm{x}$ que intercepta o semicírculo de raio a isto é, $\mathrm{H}=\sqrt{a^{2}-x^{2}}$. Nesse caso o problema de otimização também pode ser resolvido utilizando a desigualdade das médias, como no problema 1.

Uma outra forma de representar a mesma área, é por meio da imagem da função $\mathrm{A}=\mathrm{g}(\alpha)$, onde a variável $\alpha$ representa o ângulo entre o semieixo direito das abcissas e o segmento que contém o vértice superior direito do retângulo, como mostra a figura 7 . Nesse caso, utilizando as relações trigonométricas no triângulo retângulo com hipotenusa a, teremos $\mathrm{A}=2 a^{2} \operatorname{sen}(\alpha) \cos (\alpha)$. Novamente A é um produto de funções, uma delas crescente e outra

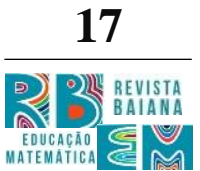
decrescente, no intervalo de variação de $\alpha$, ou seja, no primeiro quadrante, logo o problema parece ter o mesmo nível de dificuldade. Mas, utilizando propriedades da função seno, chegamos a uma solução rapidamente.

O item f) do problema é interessante para se discutir solução exata e solução aproximada, que é o que se pode obter neste caso.

O problema 3 pode ser utilizado para discutir função composta, o que ela realmente significa e como pode ajudar a facilitar a resolução de problemas.

O último problema envolve otimização de uma função afim de mais de uma variável. Foi escolhido como uma proposta mais criativa de revisar e consolidar a aprendizagem de conceitos de Álgebra e Geometria Analítica ensinados no Ensino Médio e que são importantes nos cursos superiores da área de Ciências Exatas. O estudo desse tipo de problemas pode contribuir muito para despertar a curiosidade dos alunos e para estimular o gosto pelo estudo adicional da Matemática, pois possuem uma grande aplicabilidade em situações concretas do mundo moderno, tais como reduzir custos, aumentar lucro, obter 


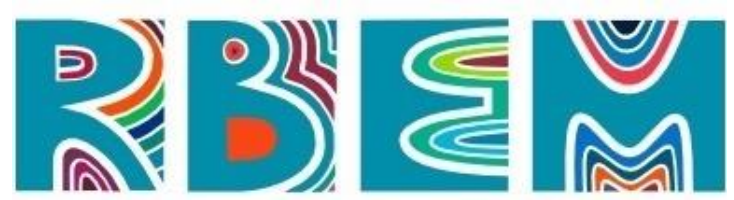

REVISTA BAIANA DE EDUCAÇÃO MATEMÁtICA

melhor rota de transporte, a dieta mais adequada, etc. De modo geral formam um conteúdo conhecido como PPL (problemas de programação linear). Quando restritos a funções de duas variáveis, o MERP parece ser uma ferramenta pedagógica adequada para explorá-los e resolvê-los.

De acordo com Boldrini (1984) e Puccini(1972), uma função afim de duas variáveis, ou seja cuja imagem é expressa por $f(x, y)=a x+b y+c$, a ser minimizada ou maximizada, é chamada função objetivo e as variáveis x e y são denominadas variáveis de decisão. Essas variáveis satisfazem, em geral, certas restrições, representadas por equações ou inequações lineares. Os pares ordenados que satisfazem a todas as restrições são denominados soluções viáveis. Uma região poligonal $\Omega$, convexa, formada por todas as soluções viáveis é chamada região viável. A solução ótima será o ponto de $\Omega$ onde a função objetivo atingir o seu valor ótimo (máximo ou mínimo). De acordo com o Teorema Fundamental da Programação Linear, se a região viável $\Omega$ é não vazia, convexa, fechada e limitada, então o máximo ou mínimo de $\mathrm{f}$ em $\Omega$ sempre existirá e ocorrerá em algum dos vértices. A princípio parece que os PPL podem ser resolvidos de forma mais algébrica que geométrica, mas, nos casos em que $\Omega$ não é limitada, o teorema não pode ser aplicado. No entanto, o método geométrico permite chegar à solução ótima, caso ela exista.

\section{Problema 4:}

Uma pessoa tem até $\mathrm{R} \$ 10.000,00$ para investir e seu gerente de banco sugere investir em dois títulos, A e B. O título A é arriscado, com lucro anual de $10 \%$ e o título B é bastante seguro, com lucro anual de $7 \%$. A pessoa resolve investir no máximo $\mathrm{R} \$ 6.000,00$ no título $\mathrm{A}$, no mínimo $\mathrm{R} \$ 2.000,00$ no título B e investir mais dinheiro no título A do que no título B.

a) Como ela deve investir seu dinheiro de modo a ter lucro anual máximo?

b) Se o lucro anual com os dois títulos for de $10 \%$, como ela deve investir? (adaptado de BOLDRINI,1984, p.399)

\section{Solução:}

a) O lucro máximo é definido pela função objetivo $f$, cuja imagem é expressa por $f(x, y)=$ 0,10x + 0,07 y. As variáveis de decisão x e y são as quantias investidas nos títulos $\mathrm{A}$ e B, respectivamente. As restrições são representadas pelas seguintes inequações: $x \geq 0$ e $y \geq 0$; $x \leq 6000 ; y \geq 2000 ; x \geq y ; x+y \leq 10000$ e determinam a região viável $\Omega$ da figura 8 . 


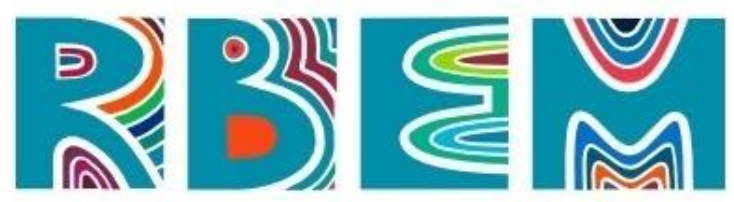

REVISTA BAIANA DE EDUCAÇÃO MATEMÁtICA

As restrições $x \geq 0$ e $y \geq 0$ remetem ao primeiro quadrante.

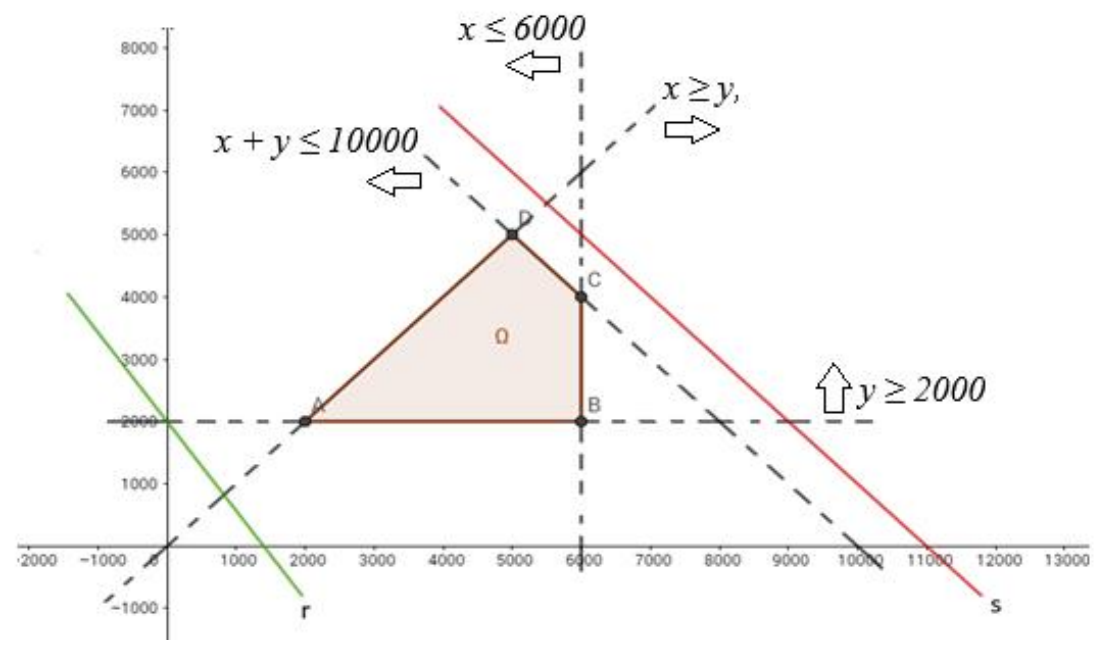

Figura 8 - região viável $\Omega$ e retas $\mathbf{r}$ e $\mathbf{s}$ (elaborada pelos autores)

Para obter a solução ótima no nosso caso, isto é, o lucro máximo, usando o MERP, procederemos da seguinte forma: para cada valor fixado de $f(x, y)=L$, os pontos $(x, y)$ do plano cartesiano que implicarão nesse lucro serão os pontos da reta $L=f(x, y)=0,10 x+0,07$ $\frac{19}{\text { D. BEEIISTA }}$ $\mathrm{y}$, isto é, pertencentes à reta $\mathrm{y}=\frac{\mathrm{L}}{0,07}-\frac{0,10}{0,07} \mathrm{x}$. Por exemplo, para um lucro $\mathrm{L}=0$, teremos os pontos $(\mathrm{x}, \mathrm{y})$ da reta $\mathrm{y}=-\frac{0,10}{0,07} \mathrm{x}$. Aumentando o lucro, teremos os pontos de uma reta paralela a essa (como a reta $\mathrm{r}$ em verde da figura 8), porque tem o mesmo coeficiente angular, mas com coeficiente linear igual a $\frac{\mathrm{L}}{0,07}$. Assim, quanto maior o valor do lucro, maior será o coeficiente linear da reta. Utilizando as ferramentas do GeoGebra deslizamos essas retas paralelas de modo que o coeficiente linear aumente e que elas intersectem a região viável $\Omega$. $\mathrm{O}$ maior valor para o lucro $\mathrm{f}(\mathrm{x}, \mathrm{y})=\mathrm{L}$ será alcançado quando for determinada a reta com o maior coeficiente linear que intersectar a região $\Omega$, o que significa que todas as restrições sobre $(\mathrm{x}, \mathrm{y})$ estarão cumpridas. A reta procurada será a que intersecta o vértice $\mathrm{C}$ da região $\Omega$ na figura 8. Como a região viável $\Omega$ satisfaz as condições do Teorema Fundamental, podemos concluir que a solução ocorrerá num dos vértices, mas a representação geométrica da situação-problema de forma dinâmica fornece o vértice exato, então o lucro máximo será $f(C)=880$, quando $x=6000$ e $y=4000$. 


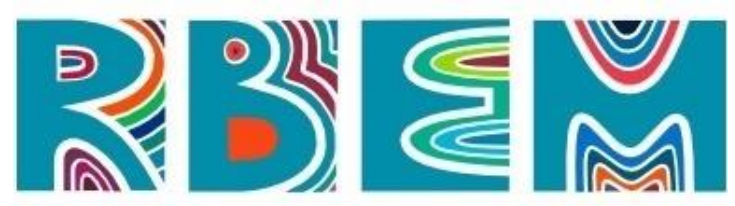

REVISTA BAIANA DE EDUCAÇÃO MATEMÁtICA

b) A região viável $\Omega$ é a mesma da figura 8 , mas a função $\mathrm{f}$ terá imagem expressa por $\mathrm{f}(\mathrm{x}, \mathrm{y})=$ $0,10 \mathrm{x}+0,10 \mathrm{y}$. Nesse caso as retas paralelas serão da forma $\mathrm{y}=\frac{\mathrm{L}}{0,10}-\mathrm{x}$, (como a reta $\mathrm{s}$ em vermelho na figura 8), cujo coeficiente angular é o mesmo que o da reta que contém o segmento CD da figura 8. Logo, com auxílio do Geogebra verificamos que a reta que tem o maior coeficiente linear e que ainda intersecta $\Omega$ será exatamente a que contém $C D$, concluímos então que todos os pontos do segmento CD são soluções ótimas, determinando o lucro máximo de $\mathrm{R} \$ 1000,00$.

Ao tentar pular etapas os alunos poderão transformar as desigualdades em igualdades, determinar as retas associadas a elas e representá-las geometricamente para assim determinar geometricamente a região $\Omega$. Isso pode levar a uma região errada e pode conduzir a uma discussão muito importante sobre vetor diretor, associado a regiões determinadas por desigualdades e como representar estas regiões no plano cartesiano.

Caso os alunos comecem a utilizar procedimento mecânico algébrico de determinar os vértices e comparar o valor da função em cada um, podem ser explorados então problemas em que a região poligonal é não limitada (nesse caso não há garantia de que exista solução). Aqui se torna essencial utilizar a representação geométrica, facilitada pelo GeoGebra, para chegar a uma solução, caso exista.

Neste caso, é na manipulação do controle deslizante por professores e estudantes que reside a potencialidade pedagógica da utilização deste software. Entendemos que o GeoGebra é uma ferramenta, assim como o quadro, o giz ou o projetor de slides. E, como toda ferramenta, deve ser usada com propósitos bem definidos e claros, explorando seus recursos e potencialidades e não empregada apenas para "florear" uma aula. No caso do GeoGebra, além da própria construção de gráficos e figuras geométricas com maior precisão do que em uma construção feita à mão no quadro branco ou negro, a possibilidade da utilização para transladar a reta utilizando um controle deslizante que altera seu coeficiente linear é algo impensável no quadro branco ou negro.

Outro aspecto que merece destaque está relacionado à questão dos Registros de Representação Semiótica. Ao manipular o coeficiente linear da representação algébrica da função e visualizar a translação da reta, o estudante interage dinamicamente com diferentes 


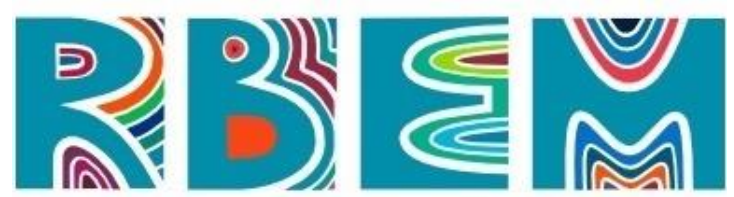

REVISTA BAIANA DE EDUCAÇÃO MATEMÁtICA

representações semióticas, a algébrica e a geométrica, e isto segundo a teoria de Duval (2006, 2009), potencializa as aprendizagens.

\section{Considerações Finais}

O Método de Ensino por Meio da Resolução de Problemas combina raciocínio geométrico e algébrico, para melhor compreensão da natureza do problema e para atingir com segurança a sua solução. Não temos a pretensão neste texto de afirmar que o MERP se configura como uma forma revolucionária ou inovadora de ensino de Matemática, e sim de propor que ideias sustentadas por pesquisas teóricas e experimentais já existentes e consolidadas sejam unidas e implementadas no Ensino. Entendemos que a Resolução de Problemas como uma estratégia de ensino e a Teoria dos Registros de Representação Semióticas podem contribuir para a melhoria do ensino de Pré-Cálculo, Cálculo Diferencial e Integral, Programação Linear e Geometria Analítica. Tal afirmação está sustentada pelos diversos estudos apresentados neste trabalho.

Por sua vez, o GeoGebra pode transformar - já está transformando - o modo como ensinamos e como os alunos aprendem. A facilidade de acesso ao aplicativo, as inúmeras BalAil Endegho possibilidades de atividades fazem do GeoGebra uma poderosa ferramenta de ensino. Neste sentido o MERP se configura não somente como uma alternativa para o ensino, mas como algo que deve ser testado, aperfeiçoado e pode inspirar outras práticas pedagógicas.

Considerando a complexidade e diversidade existente nos processos de ensino, as reflexões agregadas a este método talvez ofereçam contribuições significativas à aprendizagem de Matemática. Como diria um renomado e conhecido físico, para descobrir novos caminhos, é necessário sair dos trilhos. Que tal tentarmos?

\section{Referências}

ABRAMOVICH, S. Computers in Mathematics Education: An Introduction. In: Computer in the Schools 30 (1-2): 4-11. 2013.

ARBAIN, N.; SHUKOR, N.A. The effects of GeoGebra on students achievement. Global Conference on Business \& Social Science- Kuala Lumpur, 2014. In: Procedia-Social and Behavioral Sciences, 172, p. 208-214. 2015. 


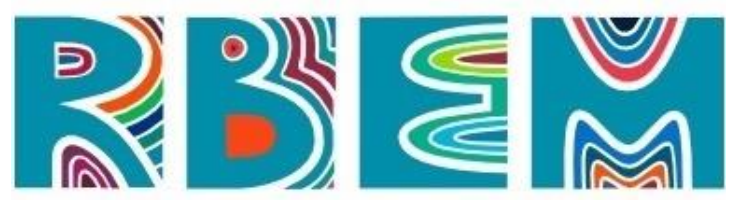

REVISTA BAIANA DE EDUCAÇÃO MATEMÁtICA

ANDRADE, F. C. O Pré-Cálculo na formação inicial do professor de matemática: múltiplos olhares. 2020. 212f. Tese (Doutorado em Ensino e História da Matemática e da Física) Instituto de Matemática, UFRJ, Rio de Janeiro, 2020.

ANDRADE, A. A.; SANTOS, C. A. B. Um Cenário das Pesquisas envolvendo a Teoria Dos Registros de Representação Semiótica em edições do SIPEM. REnCiMa, v. 10, n.1, p. 228245, 2019.

BARUFI, M. C. B. A Construção/ Negociação de Significados no Curso Universitário Inicial de Cálculo Diferencial e Integral. 1999. Tese (Doutorado em Educação). Faculdade de Educação, USP, São Paulo, 1999.

BIAZUTTI, A.C.; NASSER, L.; TORRACA, M.; BARROS, J.; OLIVEIRA, A. Conversão de Representações na transição do Ensino Médio para o Superior. In: CONGRESO ARGENTINO DE EDUCACIÓN MATEMÁTICA, XIII, 2018, La Plata. Anais... Universidad Nacional de La Plata. La Plata, 2018.

BIAZUTTI, A.C.; VAZ, R.F.N.; FERREIRA, M. Explorando problemas desafiadores de otimização no Ensino Médio com o Geogebra, 2018. In: ENCONTRO ESTADUAL DE EDUCAÇÃO MATEMÁTICA, VII. Anais... UERJ, Rio de Janeiro, 2018.

BIAZUTTI, A.C.; ANDRADE, L.; VAZ, R.F.N. Contribuições para o ensino de Cálculo: reflexões do grupo Transição do Projeto Fundão-UFRJ. In: SEMINÁRIO DE PESQUISA EM EDUCAÇÃO MATEMÁTICA, IX, 2020, ed.virtual. Anais..., 2020.

BOLDRINI, J. L., Algebra Linear. Ed. Harbra, 1984

BRASIL. Ministério da Educação e Cultura. Base Nacional Comum Curricular. 2017. Disponível em: $<$ http://basenacionalcomum.mec.gov.br/images/BNCC_EI_EF_110518_versaofinal_site.pdf >. Acesso em 17 outubro. 2020.

CURY, H. N.; BORTOLI, M. F. Pensamento algébrico e análise de erros: Algumas reflexões sobre dificuldades apresentadas por estudantes de cursos superiores. Revista de Educação, Ciências e Matemática. Rio de Janeiro, v.1. n.1, 2011.

DUVAL, R.. Semiósis e Pensamento Humano: registros semióticos e aprendizagens intelectuais. Coleção contextos da ciência - fasículo1. Tradução de Lênio Fernandes Levy e Maria Rosâni Abreu da Silveira. São Paulo: Livraria da física, 2009.

DUVAL, R.; MORETTI Trad M. T. Registros de representação semiótica e funcionamento cognitivo do pensamento ( Registres de représentation sémiotique et fonctionnement cognitif de la pensée). Revista Eletrônica de Educação Matemática, v. 7, n. 2, p. 266-297, 2012.

GERÔNIMO, J. R.; BARROS, R. M.; FRANCO, V. S. Geometria euclidiana - um estudo com o software GeoGebra. Maringá: EDUEM, 2010.

GONÇALVES, C. F. Dificuldades em matemática ao ingressar no Ensino Superior. Trabalho de conclusão de curso apresentado ao curso de Licenciatura em Matemática no Centro Universitário La Salle, Canoas, RS, 2007.

KRULIK, S; RUDNIK, J.A. Reasoning and Problem Solving- A Handbook for Elementary School Teachers. Massachusetts: Allyn and Bacon, 1993. 


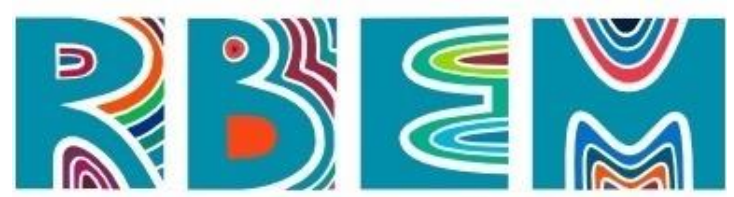

REVISTA BAIANA DE EDUCAÇÃO MATEMÁtICA

MASOLA, W. J; ALLEVATO, N. S. G. Dificuldades de aprendizagem matemática de alunos ingressantes na Educação Superior. Revista Brasileira de Ensino Superior, v.2 n.1. p. 64-74, 2016.

MATOS, J.M.; SERRAZINA, M.L. Didactica da Matemática. Lisboa: Universidade Aberta, 1996

NASSER, L.; BIAZUTTI, A. C.; BARROS, J.; VAZ, R. F. N. Resolução de Problemas como trampolim para a aprendizagem de Cálculo I. In: ENCONTRO NACIONAL DE EDUCAÇÃO MATEMÁTICA, XIII, 2019. Anais... SBEM: Cuiabá, 2019.

NASSER, L.; BIAZUTTI, A.C.; TORRACA, M.; BARROS, J. Investigando estratégias para aprimorar o desempenho em Cálculo I. In: CONFERENCIA INTERAMERICANA DE EDUCACIÓN, XIV, 2019, Medellin. Anais... CIAEM, Medellin, 2019.

REZENDE, W. M. O ensino de Cálculo: dificuldades de natureza epistemológica. São Paulo: USP, 2003. 450 p. Tese (Doutorado). Faculdade de Educação, Universidade de São Paulo, São Paulo, 2003.

ONUCHIC, L. R.; ALLEVATO, N. S. G. Pesquisa em Resolução de Problemas: caminhos, avanços e novas perspectivas. Bolema - Rio Claro (SP), v. 25, n. 41, p. 73-98, dez. 2011.

OLIVEIRA, R. A.; GONÇALVES, W. V.; PIASSON, D. O uso do Geogebra para o ensino de cálculo diferencial e integral, um mapeamento de suas publicações. Revista Thema, v. 15, n. 2, p. 466-484, 2018.

POLYA, G. A arte de resolver problemas: um novo aspecto do método matemático. Ed. Interciência, 1978.

PUCCINI, A.L., Introdução à Programação Linear. LTC, 1972

SACCARO, A.; FRANCA, M. T. A.; JACINTO, P. A. Fatores Associados à Evasão no Ensino Superior Brasileiro: um estudo de análise de sobrevivência para os cursos das áreas de Ciência, Matemática e Computação e de Engenharia, Produção e Construção em instituições públicas e privadas. Estudos Econômicos, São Paulo, vol. 49, n. 2, 2019, p. 337-373

SANTOS, D. M. M.; PINTO, G. M. F.; SOUZA, I. A.; FELIX, L. V. Atividades de tutoria: uma alternativa ao fracasso em Cálculo Diferencial e Integral. In: ENCONTRO NACIONAL DE EDUCAÇÃO MATEMÁTICA, XII, 2016, São Paulo. Anais... SBEM: São Paulo, 2016.

SIERPINSKA, A. On understanding the notion of function. In: DUBINSKY, E; HAREL, G (Ed.) The Concept of Function: aspects of epistemology and Pedagogy. MAA Notes, p.25-58, 1992.

SOUSA, G.; ANDRADE, L. Cálculo Diferencial e Integral I: como os alunos estão iniciando essa disciplina no curso de Engenharia? Atas do X ENEM, São Paulo, SP, Brasil, 2016.

TORRES, A. F. N.; HAVELANGE, L. S. Investigação dos conhecimentos de assuntos PréCálculo em estudantes da Licenciatura em Matemática. In: CONGRESSO NACIONAL DE EDUCAÇÃO, IV, 2017, João Pessoa. Anais... Campina Grande: Realize Editora, 2017.

Artigo submetido em: 17/11/2020

Artigo aceito em: 22/12/2020 